\title{
Coal grunters shift benthic objects to access macroinvertebrates in a headwater stream
}

\author{
Brendan C. Ebner ${ }^{\mathrm{A}, \mathrm{C}}$, James A. Donaldson ${ }^{\mathrm{A}}$ and Danswell Starrs ${ }^{\mathrm{B}}$
}

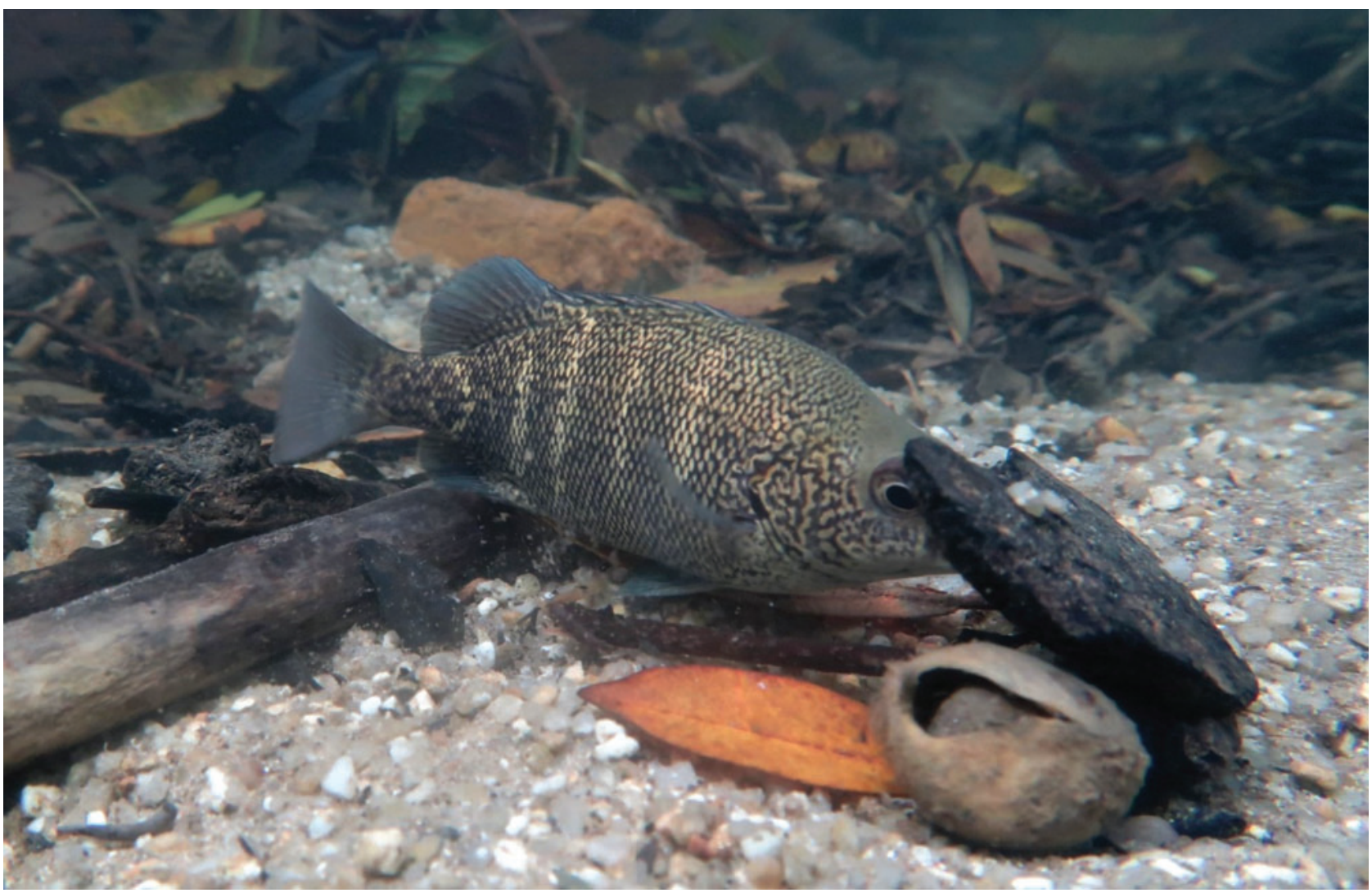

Fig. 1. A coal grunter flips a small piece of wood. Photograph by B. C. Ebner.

Despite ray-finned fishes representing the most species-rich group of vertebrates on earth, representatives from few fish families (mostly marine) have been observed using novel methods to manoeuvre objects to access prey. Specific behaviours include mouthing water jets or using fin beats to excavate prey from fine sediments, smashing prey on anvils, and pushing, flipping, lifting or carrying substrate (Jensen 2005; Brown 2012). There are no published records of these behaviours pertaining to any of the grunters (fishes of the family Terapontidae, distributed in the Indo-Pacific region and mostly inhabiting fresh waters in Australia and Papua New Guinea: Allen et al. 2002; Shelley et al. 2018). Coal grunters, Hephaestus carbo (Ogilby \& McCulloch,
1916), were observed using the mouth, snout or nape to lift, flip or roll benthic objects and expose benthic macroinvertebrates during a series of daytime snorkelling sessions in pools and runs in a clear, sandy upland tributary (3-12 m width) of the Mitchell River, northern Queensland, Australia (Fig. 1). Wood, leaves, seed pods and pebbles were pushed, flipped or rolled, usually against the flow, presumably as a function of the more stable fishbody position afforded by aligning in that direction. After exposing a new surface of the benthic object, the coal grunter typically remained very close to $(<3 \mathrm{~cm})$, or in contact with, the object while inspecting it for prey (https://youtu.be/d3apiugJriU). Occasionally, feeding strikes were made and presumably

\footnotetext{
${ }^{A}$ TropWATER, James Cook University, Townsville, Qld 4811, Australia.

${ }^{B}$ Research School of Biology, Australian National University, Canberra, ACT 2601, Australia.

CCorresponding author. Email: brendan.ebner@csiro.au
}

Received 16 April 2018

Accepted 24 June 2018

Published online 13 August 2018

Additional keywords: animal behaviour, fish ecology, habitat interactions 
macroinvertebrates including dipterans, ephemeropterans and trichopterans were consumed (since these were found on the underside of a subset of objects turned by the snorkeler). Manoeuvrability of the eyes, and specifically the temporary forward orientation of the pupils, is presumably a key adaptation of coal grunters in performing this foraging behaviour.

Medium-sized individuals (50-150 $\mathrm{mm}$ total length; TL) were common $(\sim 15-30$ individuals per field visit) and they occasionally exhibited object-shifting behaviour. Too few $(0-3$ individuals per field visit) small juveniles $(<50 \mathrm{~mm}$ TL) were observed to enable an assessment while larger individuals (150-200 mm TL) (2-5 individuals per field visit) that were present did not shift objects. This may reflect the ontogenetic dietary progression of coal grunters from consuming benthic macroinvertebrates as juveniles to targeting crustaceans, fishes and surface insects as adults (Davis et al. 2012) and/or it may reflect insufficient observational effort and/or differing observer effects on fish according to their body size. Two other grunter species were present at the site, Leiopotherapon unicolor and Hephaestus fuliginosus, and although these species occasionally flanked a coal grunter undertaking the shifting of an object (and at times $H$. fuliginosus even bullied coal grunters away from recently reoriented objects), these other grunter species did not exhibit the object-shifting behaviour. Object-shifting behaviour has been observed in at least two species of Percina (family Percidae) in fresh waters in North America (Keast and Webb 1966; Burkhead 1983; Rosenberger and Angermeier 2003); however, this type of behaviour is extremely rare among freshwater fishes in Australia and globally.

\section{Conflicts of interest}

The authors declare no conflicts of interest.

\section{Acknowledgements}

This paper did not receive any specific funding.

\section{References}

Allen, G. R., Midgley, S. H., and Allen, M. (2002). 'Field Guide to the Freshwater Fishes of Australia.' (Western Australian Museum: Perth.)

Brown, C. (2012). Tool use in fishes. Fish and Fisheries 13, 105-115. doi:10.1111/J.1467-2979.2011.00451.X

Burkhead, N. M. (1983). Ecological studies of two potentially threatened fishes (the orangefin madtom, Noturus gilberti and the Roanoke logperch, Percina rex) endemic to the Roanoke River drainage. Final Report to the US Army Corps of Engineers, Wilmington, NC.

Davis, A. M., Pusey, B. J., and Pearson, R. G. (2012). Trophic ecology of terapontid fishes (Pisces: Terapontidae): the role of morphology and ontogeny. Marine and Freshwater Research 63, 128-141. doi:10.1071/ MF11105

Jensen, G. C. (2005). A unique feeding method by a teleost fish, the fourhorn poacher Hypsagonus quadricornis (Agonidae). The Biological Bulletin 209, 165-167. doi:10.2307/3593106

Keast, A., and Webb, D. (1966). Mouth and body form relative to feeding ecology in the fish fauna of a small lake, Lake Opinicon, Ontario. Journal of the Fisheries Board of Canada 23, 1845-1874. doi:10.1139/F66-175

Rosenberger, A., and Angermeier, P. L. (2003). Ontogenetic shifts in habitat use by the endangered Roanoke logperch (Percina rex). Freshwater Biology 48, 1563-1577. doi:10.1046/J.1365-2427.2003.01109.X

Shelley, J. J., Morgan, D. L., Hammer, M. P., Le Feuvre, M. C., Moore, G. I., Gomon, M. F., Allen, M. G., and Saunders, T. (2018). 'A Field Guide to the Freshwater Fishes of the Kimberley.' (Murdoch University Print Production Team: Perth.) 